\title{
Anesthetic Dilemma: Spinal Anesthesia in a Severe Pre-Eclamptic Patient with Twin Gestation, Heart Failure and Acute Pulmonary Edema
}

\author{
E. O. Oyebamiji ${ }^{*}$, B. B. Osinaike1, B. T. Olaifa1, A. A. Adeniji ${ }^{2}$ \\ ${ }^{1}$ Department of Anesthesia, Ladoke Akintola University of Technology Teaching Hospital, Osogbo, Nigeria \\ ${ }^{2}$ Department of Obstetrics \& Gynecology, Ladoke Akintola University of Technology Teaching Hospital, Osogbo, \\ Nigeria \\ Email: droyebamiji@gmail.com
}

Received 10 February 2015; accepted 10 April 2015; published 13 April 2015

Copyright (C) 2015 by authors and Scientific Research Publishing Inc.

This work is licensed under the Creative Commons Attribution International License (CC BY). http://creativecommons.org/licenses/by/4.0/

(c) (i) Dpen Access

\begin{abstract}
Background: Severe preeclampsia with acute pulmonary oedema possesses great challenges to the anaesthetist. If not well managed, it could be associated with high maternal morbidity and mortality rate as well as fetal wastage. Aim: To sensitize the anaesthetist that when confronted with such a dilemma, well managed low spinal block can be a useful and successful anaesthetic technique. Methods: We report the case of a 23-year-old primigravida with twins gestation at 36 weeks, who presented with severe ante-partum pre-eclapsia, acute pulmonary oedema and acute heart failure. Blood investigations done were normal, and clotting time was within normal range. Her clinical conditions were optimized through a well thoughtful medication after which a low dose spinal anesthesia was performed using $1.5 \mathrm{mls}(7.5 \mathrm{mg})$ of $0.5 \%$ hyperbaric bupivacaine (Modified saddle). The baby was delivered through a low segment caesarean section. Conclusion: The procedure was well tolerated and successful. Low spinal is associated with low incidence of hypotension and do not require pre-loading.
\end{abstract}

\section{Keywords}

Severe Preeclampsia, Pulmonary Edema, Anesthetic Management, Poor Resource Setting

\section{Introduction}

Pregnancy-induced hypertension (PIH) and preeclampsia are the most common medical complications of preg-

How to cite this paper: Oyebamiji, E.O., Osinaike, B.B., Olaifa, B.T. and Adeniji, A.A. (2015) Anesthetic Dilemma: Spinal Anesthesia in a Severe Pre-Eclamptic Patient with Twin Gestation, Heart Failure and Acute Pulmonary Edema. Open Journal of Obstetrics and Gynecology, 5, 208-212. http://dx.doi.org/10.4236/ojog.2015.54030 
nancy and will be encountered in varying degree of severity by obstetric anaesthetist. Preeclampsia is more important than hypertension alone because of the associated alterations in cardiovascular, renal, coagulation, hepatic function and central nervous system as well as poor fetal outcome.

Pre-eclampsia remains a leading cause of maternal mortality in pregnancy in the world and results in $0.4 \%$ $11.9 \%$ mortality of the patients [1]. Perinatal mortality occurs in $20 \%-30 \%$ of affected mothers [1]. It is a pregnancy induced disorder with complex etiology. It mostly occurs between 33 and 37 weeks of gestation [1]. The choice of anaesthesia for caesarean section in patient with severe pre-eclampsia remains controversial [2]. The disadvantages of general anaesthesia in this type of patients have been discussed extensively [3] [4]. Regional technique is also considered unsafe [4]. Choosing between spinal and epidural block is even more wildly debated [5]. Epidural block is favored as it provides greater maternal hemodynamic stability [5].

More often than not, the anaesthetists are often presented with a patient like this in poor resource setting where there is paucity of anesthethetic options. We present a typical case of severe pre-eclampsia with acute pulmonary edema, and cardiac failure managed in our centre.

\section{Case Report}

Mrs. O. E. was a 23-year-old primigravida carrying twin pregnancy at 36 weeks gestation referred from a neighboring State Hospital with symptoms of severe occipito-frontal headache, blurring of vision, right upper quadrant abdominal pain, shortness of breath and cough.

Physical Examination revealed an acutely ill looking, anxious woman with breathlessness that required a semi-upright position to breath comfortably. She was on oxygen supplement via a facemask. She was very restless and irritable; there was gross pedal and pre-tibia edema. Her pulse rate was 140 beats per minute, full and regular. There was raised jugular venous pressure, systolic blood pressure was $200 \mathrm{mmHg}$ and diastolic blood pressure was $140 \mathrm{mmHg}$. Heart sounds 1 \& ll with gallop rhythm. Respiratory rate of 60 cycles per minutes, wide spread transmitted sounds with scattered basal fine crepitations. Estimated gestational age using the height of fundus was 36 weeks, fetal heart rate was 140 beats per minute, and 3+ proteinuria. A working diagnosis of severe pre-eclampsia in a primigravida with twin pregnancy, complicated by acute pulmonary edema and congestive cardiac failure [CF] was made.

She was admitted into labour ward and treated with hydrallazine $20 \mathrm{mg}$ i.v. stat. Aldomet 500 mg 12 hourly and frusemide $60 \mathrm{mg}$ i.v. stat, and supplemental oxygen via face mask. Medical consultation was sent to the cardiologist, who made a working diagnosis of severe hypertension in pregnancy with acute pulmonary edema and heart failure. He therefore placed the patient on sublingual nifedipine $20 \mathrm{mg}$ stat., followed by oral aldomet 250 mg q8hrly. Urgent full blood count, coagulation profile and blood biochemistry were requested. Hematocrit was $10 \mathrm{~g} / \mathrm{dl}$, bedside bleeding time was 5 minutes which is within normal value, electrolytes and urea values were within normal range. Electrocardiogram could not be done as facility for it was not immediately accessible.

Following further review by the Consultant Anaesthetist and Obstetrician a joint decision was made to urgently deliver the patient by emergency caesarean section. Patient was transferred to the operating room. All available options were considered and final decision was to proceed with low spinal anaesthesia.

At induction room baseline vital signs were taken and recorded. Pulse rate was 160 beats per minute, blood pressure was $150 / 110 \mathrm{mmHg}$. $\mathrm{SaO}_{2}$ was $98 \%$, on $100 \%$ oxygen supplementation. Pre-loading was avoided for fear of worsening the pulmonary edema and cardiac failure. Subarachniod block was established using a 25 gauge quincke needle, and injecting $1.5 \mathrm{ml}(7.5 \mathrm{mg})$ of $0.5 \%$ hyperbaric bupivacaine into the subarachnoid space. Patient remains seated for 5 minutes before she was turned to left lateral with $30^{\circ}$ head-up-tilt. Level of blocked was up to $\mathrm{T}_{10}$ using sterile pin prick.

Monitoring was done using Schiller ARGUS. TM.7 attached to patient, for continuous non-invasive monitoring of blood pressure, pulse oximetry, temperature and electrocardiogram (ECG). Post spinal blood pressure of 140/90 mmHg was maintained till after the delivery of the babies when there was a sudden drop in blood pressure to $100 / 60 \mathrm{mmHg}$. This sudden drop in blood pressure responded well to fluid administration. About ten minutes to the end of the operation she complained of pain arising from external pressure on the uterus. Intravenous administration of $30 \mathrm{mg}$ pentazocine restored perfect analgesia. The procedure was well tolerated and satisfactory to the patient. The procedure took about 40 minutes and estimated blood loss was 0.8 litres. Patient did well post-operatively and she was discharged to the cardiologist on the $10^{\text {th }}$ post-operative day, with Blood pressure of 140/90 mmHg. 
Follow up: Patient was followed up at the cardiac clinic for about four months before she defaulted. During that period of follow up she complied with medication her condition was much better, her blood pressure was well maintained at 130/90 mmHg. She defaulted and finally lost to follow-up.

\section{Discussion}

Pre-eclampsia may be defined as pregnancy induced hypertension with proteinuria, developing in the third trimester of pregnancy or for the first time in labour. It occurs in approximately $10 \%$ of pregnancies [6], most commonly between 33 weeks and 37 weeks gestation [6]. The ultimate cure is delivery of the baby and the placenta [6]. Though the etiology of pregnancy induced hypertension is not known, the pathophysiology of this disease is well documented. The basic pathology of this syndrome was attributed to endothelial damage which is considered to be the initiation of multiple organs disease and dysfunctions [7]-[10].

Though the severity in presentation of pre-eclampsia varies from different parts of the world, it remains a major contributor to maternal and fetal morbidity and mortality. The basis of management remains the same.

The ominous signs in severe pre-eclampsia are acute respiratory distress syndrome (ARDS), cerebral edema, intracranial haemorrhage, pulmonary edema and ruptured liver.

Severe pre-eclampsia is a condition in which the systolic arterial blood pressure is above $160 \mathrm{mmHg}$, and diastolic blood pressure above $110 \mathrm{mmHg}$ and mean-arterial blood pressure above $120 \mathrm{mmHg}$, proteinuria, often accompanied by oliguria, headache, cerebral disturbances, visual disturbances, epigastric pain, pulmonary edema and HELLPS. Severe pre-eclampsia/eclampsia remains one of the leading causes of maternal and perinatal morbidity and mortality in developing countries [6]. Being a primigravida and unbooked for antenatal care, with delay in hospital presentation is typical of pre-eclampsia/eclampsia in developing countries [6]. Patients with severe pre-eclampsia present a significant anesthetic dilemma. The presence of severe hypertension, contracted intravascular volume and multiple organs dysfunction requires an anesthetic technique that will ensure hemodynamic stability [3] [4].

There is no doubt that the uterus provides the best environments for the baby but, in severe pre-eclampsia it is the contrary and the delivery of the baby must be expedited. However, it is important that the mother's condition is stable before anaesthesia. Delivery may be delayed for a few hours to allow hemodynamic stability and optimization of maternal conditions.

Urgent delivery gets the mother out of the life threatening conditions but in the present case quite a number of adverse factors militate against the normal conduct of anaesthesia and surgery; these were

- Poorly controlled hypertension

- Pulmonary edema

- Severe respiratory distress

- Cardiac failure

The challenges facing us was how best to deliver this patient safely in a setting with limited anesthetic options. General Anaesthesia in the presence of pulmonary congestions and imminent congestive cardiac failure will not be the best option for this patient, as it can worsen the maternal condition. Regional anaesthesia was considered, but regional technique in the presence of heart failure must avoid marked hemodynamic changes and tachycardia [11].

Incremental epidural is favored in many standard textbooks, but it is not without its own drawbacks such as unintentional dural puncture, inadequate analgesia and unexpected high block.

Spinal anaesthesia is generally considered superior to epidural anaesthesia for caesarean section because of more predictable distribution of block as well as a denser block. However, rapid onset of a spinal and its marked cardiovascular changes made it a delicate choice for the present case.

Low dose combined spinal-epidural anaesthesia combines the quality of spinal anaesthesia with a slower onset of block than single-shot technique [12]. Low dose combine spinal-epidural halves the incidence of hypotension compare with normal dose of single shot [12]. However, the use of low dose combined spinal-epidural in routine anesthetic practice is not available in our centre.

David Wilkinson [13] in his studies demonstrated the use of low spinal (single shot) in caesarean sections. He injected $7.5 \mathrm{mg}$ of hyperbaric bupivacaine at L3/L4, patient remains seated for 5 minutes. Patient then lies supine with a left lateral tilt and slight head-up tilt [14]. In his studies the procedures were well tolerated and satisfactory to patient. Wilkinson technique was an improvement on the use of modified saddle block for caesarean 
section described in the text book of anaesthesia [15]. Low dose spinal anaesthesia (Wilkinson's method) was tried in this patient and was found safe with satisfactory analgesia. The procedure was well tolerated and acceptable to our patient. The risk of spinal anaesthesia includes hypotension, hypoventilation, total spinal as well as failed spinal [16] [17]. There were no reported cases of high spinal or significant hypotension in Wilkinson's study. Therefore, low dose spinal was used safely for this patient without significant hypotension. Heavy marcaine was our choice because studies have shown that intrathecally administered hyperbaric bupivacaine offers a lower incidence of hypotension and a more reliable cephalad spread than isobaric or hypobaric bupivacaine [18]. The addition of an opioid with a low dose local anesthetic agent in spinal has confirmed good spinal analgesia, with associated decrease incidence of hypotension by 30\% [19].

However, the use of intrathecal opioids without resources to treat its complication is dangerous.

\section{Conclusion}

We have presented a patient with severe pre-eclampsia who was given low dose spinal anaesthesia for emergency caesarean section. Each case is unique and it is not possible to prescribe the same anesthetic technique for every eclamptic patient. However, we are of the opinion that we choose the best technique for this patient considering our limited resources, paucity of anesthetic options and the challenges presented by the complexity of the case. This technique is simple, effective and satisfying. It is recommended for people working in resources poor centers in developing countries.

\section{References}

[1] Gutsche, B.B. and Check, T.G. (1993) Anaesthetic Considerations in Pre-Eclampsia—Eclampsia. In: Shinder, S.M. and Levinson, G., Eds., Anaesthesia for Obsterics, 3rd Edition, William \& Wilkins, Baltimore, 305-329.

[2] Howell, P. (1998) Spinal Anaesthesia in Severe Pre-Eclampsia: Time for Reappraisal or Time for Caution! International Journal of Obstetric Anaesthesia, 7, 217-219.

[3] Wallace, D.H., Leveno, K.J., Cunningham, F.G., Giesecke, A.H., Shearer, V.E. and Sidawi, J.E. (1995) Randomized Comparison of General and Regional Anaesthesia for Caesarean Delivery in Pregnancies Complicated by Severe Preeclampsia. Obstetrics \& Gynecology, 86, 193-199. http://dx.doi.org/10.1016/0029-7844(95)00139-I

[4] Moodley, J., Jiuuko, G. and Rout, C. (2001) Epidural Compare with General Anaesthesia for Caesarean Delivery in Woman with Eclampsia. British Journal of Obstetrics and Gynaecology, 108, 378-382. http://dx.doi.org/10.1016/S0306-5456(00)00097-8

[5] Ramanathan, J., Coleman, P. and Sibai, B.M. (1991) Anaesthetic Modification of Hemodynamic and Neuroendocrine Responses to Caesarean Delivery in Woman with Severe Preeclampsia. Anesthesia \& Analgesia, 73, 772-779. http://dx.doi.org/10.1213/00000539-199112000-00016

[6] Jamalle, R.N. (1997) Eclapsia-A Taxing Situation in the Third World. International Journal of Gynecology and Obstetrics, 58, 311-312.

[7] Royston, E. (1989) Armstrongs. Causes of Maternal Death. In: Royston, E. and Armstrong, S., Eds., Preventing Maternal Death, World Health Organization, Geneva, 75-106.

[8] Rapaport, S.I. (1971) Introduction to Hematology. Harper and Row, New York, 282-286.

[9] Weiner, C.P. (1987) The Role of Serotonin in the Genesis of Hypertension in Eclampsia. American Journal of Obstetrics and Gynecology, 156, 885-888. http://dx.doi.org/10.1016/0002-9378(87)90345-0

[10] Molnar, M., Suto, T., Toth, T., et al. (1994) Prolonged Blockade of Nitric Oxide Synthesis in Gravid Rats Produces Sustained Hypertention, Proteinuria Thrombocytopenia and Intrauterine Growth Retardation. American Journal of Obstetrics and Gynecology, 170, 1458-1466. http://dx.doi.org/10.1016/S0002-9378(94)70179-2

[11] Le, W. (1991) Clinical Management of Gravid Woman with Peripartum Cardiomyopath. Obstetrics and Gynecology Clinics of North America, 18, 257-271.

[12] Swrami, A., Mc Hale, S., Abbotf, P. and Morgan, B. (1993) Low Dose Spinal Anaesthesia for Caesaran Section Using Combined Spinal Epidural (CSE) Technique. Anaesth-Anagesia, 76, S423.

[13] Wilkinson, D. (1993) Low Spinal Anaesthesia for Caesarian Section S. Afr. Fam Pract., 7-10.

[14] Kinsella, S.M., Whitwam, J.G. and Spencer, J.A.D. (1992) Reducing Aortocaval Compression: How Much Tilt Is Enough? BMJ, 305, 539-540. http://dx.doi.org/10.1136/bmj.305.6853.539

[15] King, M.H. (1986) Primary Anaesthesia. Oxford University Press, Oxford. 
[16] Irestedt, L. (1998) Spinal Anaesthesia for Caesarean Delivery. Acta Anaesthesiologica Scandinavica (Suppl), 42, 21-23. http://dx.doi.org/10.1111/j.1399-6576.1998.tb04982.x

[17] Finucane, B.T. (1995) Spinal Anaesthesia for Caesarean Delivery. The Dose Dilemma. Reg. Anesth., 20, 87-89.

[18] Vercautesen, M.P., Coppejans, H.C., Hoffmann, V.L., Saldien, V. and Adriaensen, H.A. (1998) Small-Dose Hyperbaric versus Plain Bupivacanine during Spinal Anaesthsia for Caesarean Section. Anesthesia and Analgesia, 86, 989-993.

[19] Ben-David, B., Miller, G., Gavriel, R. and Gurevitch, A. (2000) Low Dose Bupivcacaine-Fentanyl Spinal Anaesthesia for Caesarian Delivery. Regional Anesthesia \& Pain Medicine, 25, 235-239.

http://dx.doi.org/10.1097/00115550-200005000-00005 